575 CHILD SEXUAL ABUSE IN BULGARIA: A NEED FOR POLICY CHANGE

Petya Trendafilova. Medical University - Sofia, Faculty of Public Health, Sofia, Bulgaria

10.1136/injuryprev-2016-042156.575

Background (issue/problem) Sexual abuse has a long-term impact on the child's development. Children victims of sexual abuse become more often abusers. Child abuse is no longer a private problem. We should change the perspective and put an accent on the responsibility of the country and the whole society.

Description of the problem There is a high tolerance against child sexual abuse in Bulgarian society. This tolerance can be found within the family, the public opinion, and even within the institutions like schools, kinder gardens and other institutions responsible for upbringing of children at risk, as well as the police, the prosecutors and the court. An insufficient synchronisation in the legislation exists, especially the interaction and coordination between the institutions and the justice system. Usually investigations have been carried out for years with no result in Bulgaria.

Results (effects/changes) In 2013 the total numbers of reported cases (new and old cases) of child sexual abuse were 304 according to the State Agency for Child Protection (SACP). It is about $15.4 \%$ of all types of violence against children. For comparison, in 2012 the number of sexual abused children is 324 or $15.3 \%$ of all types of violence. There is a lack of data about the support those victims have received and about the work done by the responsible institutions. There are limited programs for psychological help for victims of sexual abuse at the institutions and no programs developed to work within the family.

Conclusions The services for children victims of violence in Bulgaria are insufficient. It is quite important to create a society, public opinion, legislation, institutions, professionals and policy that are sensitive and intolerant to the child sexual abuse issue and to adopt common standards for people working with children. Transparent data about the services available for victims of sexual abuse and services provided to those who needed them. Continuing training of professionals working with victims of child sexual abuse has to be implemented. Appropriate supervision of activities with children has to be applied. Functioning penal system and functioning child protection system for victims of sexual abuse is needed.

\section{EPIDEMIOLOGY OF NON-FETAL VIOLENCE AGAINST WOMEN IN THE RURAL AREA OF BANGLADESH}

Asma UI Hosna, Abu Talab, Salim Mahmud Chowdhuary, Jahangir Hossain. Centre for Injury Prevention and Research, Bangladesh

\subsection{6/injuryprev-2016-042156.576}

Background Each year more than 1.3 million people worldwide die as a result of violence in all its forms (self-directed, interpersonal and collective), accounting for $2.5 \%$ of global mortality. Recent global prevalence figures indicate that $35 \%$ of women worldwide have experienced either intimate partner violence or non-partner sexual violence in their lifetime. The first report of the "WHO Multi-country study on women's health and domestic violence against women" (2005) found that, among women aged $15-49,30 \%$ in rural Bangladesh reported that their first sexual experience was forced. Our study aims at exploring the extent and associated factors of violence against women in a low-and middle-income country (LMIC) setting.
Methods A community base active surveillance system around $6,56,115$ population was established in three upazillas (Raiganj, Sherpur, Manohardi) of Bangladesh in 2009 July to 2010 June. Data on Injury and other health event are being collected by chain surveillance data collector. We have analysed the mentioned one year data.

Results A total of 694 violence incidents were identified during the reporting period and 281 cases were violence against women. It is also revealed that $>18$ age group of women were mostly victimised. $93 \%$ of the cases were caused due to quarrel or fight. Most of the violence against women occurred by their husband (23\%) and known non relatives (21\%).

Conclusions The findings of this study could be the knowledge based for the policy maker in addressing these inhuman acts as well as improving medical care for the victims.

\section{Youth Violence}

\section{Post Mon 1.16}

\section{YOUNG GIRLS EXPERIENCES OF PEER VIOLENCE}

Tordis Kristine Sovde. University of the Artic, Norway

\subsection{6/injuryprev-2016-042156.577}

Background The purpose of the study was to develop knowledge about violence among teenagers, espcially young girls and their strategies and capacities to deal with this. The population of the Northern Region of Norway statistically is exposed to a greater extent of violence compared with the rest of the country. In the Norwegian context the national criminal statistics show that $24 \%$ of the $\%$ of the boys og $12 \%$ girls are exposed to violence.

Methods This paper investigates if and how girls aged 13-22 years in the Finnmark county of Norway experience actions of violence in their relationships of peers as well as their capacities to deal with such incidents. The eleven interviews were semistructured quality interviews, based on an interview guide, They were documented anonymously, recorded, transcribed and finally analysed by categorization into themes (Kvale 2009). They were one in depth interview eleven The theoretically approaches were based on the social constructive views.

This project was two year study, financed by Sanks, the Sami National Competence Centre of Youth Pscychiatry. by my colleague, Monica Bjerklund, and myself being assistant professors of social work at the Finmark University College, Alta, Norway The project was a follow-up of our former Media Analysis of Youth Violence in the regional papers The eleven female informants were recruited through a Sami boarding school, and the informants came from different places in the county. Norwegian legislation has strict rules about confidentiality and age, but these were avoided since our eleven informants were 18 years of age, the Norwegian age of majority. at the time of the interview The Norwegian National Board of Research Ethics were asked of permission, and did not give any research restrictions of interviewing those young girls.

Results

- The findings show that all the girl informants Finmark Norway had experienced violence among their peers

- The analyses of the interviews illustrated the variations of violence from the the young girls had been exposed to, some as witnesses, or different kinds of physical and psyic violence and threaths from rape to physically bullying. 
- Some girls had beaten and kicked other girls as a revenge for «stealing» their boyfriends.

- Two girls had assaulted a boy on the homeway from their school.

- Some of the informants with experiences as victims of bullying at school, felt they did not get help but were met by passively and partly belittteling attitudes.from the schools and authorities.

- One aspect is that most of of the girl victims had kept quiet and told nothing to their families and friends about those incidents

- Another aspect is that to stop the violence some of them had moved to another place to get away from the perpetrator, often by presentig other reasons for moving,

Conclusions Young girls are more exposed as the victims of the youth violence than parents and the authorities know about. Some of the young girls feel to ashamed to tell their parents. It is important to identify the need for help to the young victims, and make good programs for preventions as well as advocating for increased political will and greater attention and resources for raising awareness about the problem of youth violence.

\section{FREE2B: BRIDGING THE GAP BETWEEN THEORY, PRACTICE \& INNOVATION IN BULLYING PREVENTION PROGRAMMING}

${ }^{1,2}$ Stephen S Leff, 'Tracy E Waasdorp, 1,2Flaura K Winston. ${ }^{1}$ The Children's Hospital of Philadelphia, Philadelphia, PA USA; ${ }^{2}$ The Perelman School of Medicine at the University of Pennsylvania, Philadelphia, PA, USA

\subsection{6/injuryprev-2016-042156.578}

Background Urban minority youth are disproportionately exposed to violence, a factor that perpetuates disparities in education, incarceration, and social/behavioural problems. Involvement in bullying in early adolescence has been associated with maladaptive outcomes as youth enter young adulthood. Combining state-of-the-art interactive technology, a strong theoretical foundation and a partnership-based approach with urban youth and educators, initial studies of Free2B will be examined to determine its relevance, acceptability, and initial effectiveness for urban 7 th and 8 th graders.

Methods The program theory explicates how the primary intervention components (3D film, inspirational videos and an interactive quiz show) are thought to impact both proximal (e.g., knowledge of bullying facts; prosocial attitudes about positive bystander behaviour) and distal (e.g., increases in positive bystander behaviour and collective action to prevent bullying) outcomes over time.

Results Data from 2687 th and 8th grade ethnic minority youth from two North American urban schools will be presented. Over $90 \%$ of students found the program to be acceptable and feasible. In addition, paired sample t-tests also suggest that Free2B enhanced students' social problem-solving knowledge, prosocial attitudes about bullying, and confidence in resolving conflicts. In addition, data has just been collected from ten additional schools across both urban and suburban contexts in order to better understand program applicability for a more diverse set of school contexts.

Conclusions Free2B highlights how researchers can collaborate with multi-media experts to develop engaging and scientificallygrounded injury prevention programs that can relevance for diverse urban and potentially suburban settings. Challenges for researchers in trying to bridge the gap between theory, practice, and innovation will be highlighted.

\section{Occupational Safety}

\section{Post Mon 1.17}

\section{APPLICATION OF MINI MORT AND WHY 5 METHODE TO ANALIZED AND INVESTIGATE LOSS TIME ACCIDENT (LTA) CASES (CASE STUDY IN MANUFACTURING INDUSTRIES)}

Tofan Agung Eka Prasetya. Industrial Hygiene and Occupational Health, Health Department of Vocational Faculty, Airlangga University, Surabaya, Indonesia

\subsection{6/injuryprev-2016-042156.579}

Background Through in-depth identification of management system and specific control factor, the root cause of the accident can be determined. Had been an accident in the PT.X such as a first aid injury and loss time accident, and has conducted investigations and follow-up but similar accidents still happen. The purpose of this study was to identify the cause of the accident based on management system and specific control factor.

Methods This study used qualitative approaches to explore the root cause based on management system factor and specific control factor. Researchers used a qualitative approach, because researchers used a standard mini-MORT as a data collection tool and 5 whys method to explore the root causes.

Results Results of the analysis in the first case accident that crushed by c-canal, and the second case of an accident that falling from a ladder have in common causes, which is the cause of the accident was due to organisational influences. Influence of the organisation, such as resource management, organisational climate and organisational process. This relates to the allocation of limited resources, both human and financial, and material.

Conclusions Conclusion of this study is that there are elements of the management system and specific control factor was inadequate, and the root cause of the accident was on organisational Influences. The company had to consider the approach to safety behaviour that occupational safety and health programs can be done with an awareness of the whole management to workers who are believed to reduce the number of accidents.

\section{PREVALENCE AND ASSOCIATED FACTORS OF WORK- RELATED INJURIES AMONG RUBBER TAPPERS IN SRI LANKA}

${ }^{1}$ Kayla Stankevitz, ${ }^{2,3}$ Catherine Staton, ${ }^{4}$ Ashley Schoenfisch, ${ }^{5}$ Vijitha de Silva, ${ }^{5}$ Hemajith Tharindra, ${ }^{1}$ Marissa Stroo, ${ }^{1,2}$ Truls Ostbye. 'Department of Community and Family Medicine, Duke University, USA; ${ }^{2}$ Duke Global Health Institute, Duke University, USA; ${ }^{3}$ Division of Emergency Medicine, Duke University, USA; ${ }^{4}$ Duke School of Nursing, Duke University, USA; ${ }^{5}$ Department of Community Medicine, Faculty of Medicine, University of Ruhuna, Sri Lanka

\subsection{6/injuryprev-2016-042156.580}

Background Occupational injuries are a major cause of global disability and death. Agriculture has been shown to be the most hazardous of all industries, particularly in jobs that require intense manual labour. Rubber tapping- the process of extracting rubber from rubber trees- involves sharp tools, steep terrain, and heavy loads; putting tappers at risk for injury. This study assesses injury 